\title{
PREVALENCE OF ANEMIA AND CLINICAL APPROACH IN PATIENTS DISCHARGED AFTER GASTROINTESTINAL BLEEDING
}

\author{
Goksel Bengi ${ }^{1}$, SEDA BAYRAK DURMAZ², HATICE KEYVAN ${ }^{2}$, MESUT AKARSU³ \\ MÜJDE SOYTÜRK ${ }^{3}$, ENDER BERAT ELLIDOKUZ ${ }^{3}$, ÖMER SELAHATTIN \\ TOPALAK $^{3}$, and Hale AKPINAR ${ }^{4}$ \\ ${ }^{1}$ Dokuz Eylul Univ \\ ${ }^{2}$ Dokuz Eylül University Faculty of Medicine, Department of Internal Medicine, İzmir, \\ Turkey \\ ${ }^{3}$ Dokuz Eylül University Faculty of Medicine, Department of Internal Medicine, Division of \\ Gastroenterology, İzmir, Turkey \\ ${ }^{4}$ Dokuz Eylül University
}

June 24, 2020

\begin{abstract}
Background and Aim: Acute gastrointestinal system (A-GIS) hemorrhages are frequent. Anemia is frequently seen in these patients at the discharge from the hospital. The anemia prevalence and approach to the anemia in patients with A-GIS bleeding at the time of discharge and during 3 months' follow-up has been evaluated in this study. Method: In this study 197 patients diagnosed A-GIS bleeding in our hospital between January 2017 -May 2018 have been evaluated retrospectively. Results: In 129 of these patients upper gastrointestinal endoscopy, in 3 of them enteroscopy, in 45 of them lower gastrointestinal endoscopy, in 8 of them both upper and lower gastrointestinal endoscopy, in 2 of them upper, middle and lower gastrointestinal endoscopies were applied and 10 patients didnt performed endoscopy. In 69 of these patients therapeutic endoscopic treatments were applied. The mean of the length of hospitalization was $10 \pm 13.84$ day and $67 \%$ of patients had erythrocyte transfusion with a mean value of 3.5 \pm 5.89 units during hospitalization. The mean of hemoglobin rate was $9.85 \pm 1.67 \mathrm{~g} / \mathrm{dL}$ at the time of discharge from the hospital. In $92.4 \%$ of the patients (F 91.1\%, M 93.2\%; upper GI bleeding 93.9\%, middle GI bleeding 100\%, lower GI bleeding $86.8 \%$ ) anemia was detected at the time of the discharge. In $9.7 \%$ of these patients, iron deficiency treatment were applied. $33 \%$ of all 197 patients were evaluated 3 months after discharge from the hospital and in $80 \%$ of these patients had still ongoing anemia. Conclusion: Anemia frequency is high when the patients with A-GIS bleeding are discharged. Most patients are discharged without receiving a prescription for the anemia. In follow-up, control applications are inadequate and anemia persists in patients
\end{abstract}

Manuscript Type: Original Article

prevalence of anemıa and clinıcal approach in patıents discharged after GASTROıNTESTıNAL BLEEDING

Göksel Bengi ${ }^{1}$ (Assis. Prof.), Seda Bayrak Durmaz ${ }^{2}$ (MD), Hatice Keyvan²(MD), Mesut Akarsu1 (Prof.), Müjde Soytürk ${ }^{1}$ (Prof.), Ender Ellidokuz ${ }^{1}$ (Prof.), Ömer Topalak ${ }^{1}$ (Prof.), Hale Akpınar ${ }^{1}$ (MD). ${ }^{1}$ Dokuz Eylül University Faculty of Medicine, Department of Internal Medicine, Division of Gastroenterology, İzmir, Turkey 
${ }^{2}$ Dokuz Eylül University Faculty of Medicine, Department of Internal Medicine, İzmir, Turkey

ORCID ID:

Göksel Bengi: 0000-0002-7859-4094

Seda Bayrak Durmaz: 0000-0001-8272-5686

Hatice Keyvan: 0000-0002-7032-6124

Mesut Akarsu: 0000-0001-9217-948X

Müjde Soytürk: 0000-0002-2646-639X

Ender Ellidokuz: 0000-0001-5863-3298

Ömer Topalak: 0000-0003-2699-021X

Hale Akpinar: 0000-0002-8734-2518

Author contributions: Göksel Bengi, Hatice Keyvan, Seda Bayrak Durmaz, Mesut Akarsu, Müjde Soytürk, Ender Ellidokuz, Ömer Topalak and Hale Akpınar contributed equally to this work, designed the research, drafted the manuscript and provided administrative and technical support.

Financial Disclosures: None.

Ethics Committee Approval: This study was approved by the Dokuz Eylul University Ethics Committee on July 2017 number: 2017/18-16.

Informed Consent: Informed consent was provided by all participants.

Conflicts of interest: None.

Correspondence to: Göksel Bengi, MD, PhD, Assis. Prof.,Department of Gastroenterology, Dokuz Eylul Universtiy Hospital, İnciraltı, 35000, İzmir, Turkey.drgokselbengi@hotmail.com

Telephone: $+90-532-4626972+90-232-4123713$

Fax: $+90-232-4123799$

\section{ABSTRACT}

\section{Background and Aim:}

Acute gastrointestinal system (A-GIS) hemorrhages are frequent. Anemia is frequently seen in these patients at the discharge from the hospital. Studies intended to these patients' follow up after discharge and anemia treatment are limited and there are no guidelines on this topic. The anemia prevalence and approach to the anemia in patients with A-GIS bleeding at the time of discharge and during 3 months' follow-up has been evaluated in this study.

\section{Method:}

In this study 197 patients diagnosed A-GIS bleeding in our hospital between January 2017 -May 2018 have been evaluated retrospectively. At the time of discharge, the anemia was accepted as hemoglobin levels lower than $13 \mathrm{~g} / \mathrm{dL}$ in males, $12 \mathrm{~g} / \mathrm{dL}$ in females according to the WHO criteria.

\section{Results:}

In 129 of these patients upper gastrointestinal endoscopy, in 3 of them enteroscopy, in 45 of them lower gastrointestinal endoscopy, in 8 of them both upper and lower gastrointestinal endoscopy, in 2 of them upper, middle and lower gastrointestinal endoscopies were applied and 10 patients didnt performed endoscopy. In 69 of these patients therapeutic endoscopic treatments were applied. The mean of the length of hospitalization was $10 \pm 13.84$ day and $67 \%$ of patients had erythrocyte transfusion with a mean value of $3.5 \pm 5.89$ units 
during hospitalization. The mean of hemoglobin rate was $9.85 \pm 1.67 \mathrm{~g} / \mathrm{dL}$ at the time of discharge from the hospital. In $92.4 \%$ of the patients (F 91.1\%, M 93.2\%; upper GI bleeding 93.9\%, middle GI bleeding 100\%, lower GI bleeding 86.8\%) anemia was detected at the time of the discharge. In $9.7 \%$ of these patients, iron deficiency treatment were applied. $33 \%$ of all 197 patients were evaluated 3 months after discharge from the hospital and in $80 \%$ of these patients had still ongoing anemia.

\section{Conclusion:}

Anemia frequency is high when the patients with A-GIS bleeding are discharged. Most patients are discharged without receiving a prescription for the anemia. In follow-up, control applications are inadequate and anemia persists in patients. There is a need for a wider range of patient studies on how treatment should be applied and how to follow it, as well as guidelines from the consensus body on this issue.

Key words: Acute gastrointestinal bleeding, Discharge, Anemia, Anemia treatment

\section{WHAT'S KNOWN}

Anemia and particularly iron deficiency anemia are very frequent in patients with Acute gastrointestinal bleedings. Although available studies on this subject are limited and old, anemia was found in more than two thirds of patients presenting with non-variceal upper GI bleeding, and anemia improved in the patients after approximately a 2-144-month follow up.

It is important to identify and correct anemia in patients presenting with AGI bleeding, because iron deficiency (ID) and ID anemia (IDA) have negative effects on the patient's quality of life and work environment. They cause frequent hospital admissions, delays in discharge and increased healthcare costs. Follow up studies of patients with AGI bleeding are limited and there are not sufficient studies about rates of anemia, status of iron reserves and information regarding presence or absence of sufficient iron therapy in patients presenting and discharged with AGI bleeding mainly in our country.

\section{WHAT'S NEW}

Anemia is seen at a very high rate like $92 \%$ at discharge in the patients presenting with AGI bleeding in our retrospective study and most patients are discharged without receiving a prescription for the treatment of anemia. Control presentation during follow up is inadequate and anemia persists in $80 \%$ of patients coming to follow up visits. Studies with larger number of patients about the treatment and follow up to be conducted and guidelines providing consensus on this subject are needed.

\section{INTRODUCTION}

Acute gastrointestinal (AGI) bleedings are frequent in gastroenterology emergency practice. AGI bleedings are divided into 3 groups regarding bleeding site; bleedings in the GIS tract until ampulla Vateri are upper, those between ampulla Vateri and ileocecal valve are middle and those in the distal of ileocecal valve are lower AGI bleedings. Guidelines are available regarding endoscopic approach to AGI bleedings ${ }^{1-4}$.

Anemia and particularly iron deficiency anemia are very frequent in patients with AGI bleedings (5). Although available studies on this subject are limited and old, anemia was found in more than two thirds of patients presenting with non-variceal upper GI bleeding, and anemia improved in the patients after approximately a 2-144-month follow up ${ }^{6-9}$.

It is important to identify and correct anemia in patients presenting with AGI bleeding, because iron deficiency (ID) and ID anemia (IDA) have negative effects on the patient's quality of life and work environment. They cause frequent hospital admissions, delays in discharge and increased healthcare costs ${ }^{5}$. In a recent local, retrospective study, anemia was noted during hospital discharge in more than $80 \%$ of patients presenting with upper AGI bleeding and only $16 \%$ of these patients received oral iron supplements ${ }^{10}$. In recent randomized controlled studies, significant improvements were noted in hemoglobin levels in patients treated with intravenous (IV) iron therapy compared with placebo among patients presenting with GI bleeding and found to have anemia ${ }^{11}$. 
Follow up studies of patients with AGI bleeding are limited and there are not sufficient studies about rates of anemia, status of iron reserves and information regarding presence or absence of sufficient iron therapy in patients presenting and discharged with AGI bleeding mainly in our country.

In this study, it was aimed to evaluate anemia prevalence, approach to anemia and factors affecting changes in approach, if present, during discharge from hospital and the following 3 months in patients who had upper, middle and lower AGI bleeding.

\section{MATERIALS AND METHODS}

Hundred and ninety seven patients admitted to our Hospital which is a tertiary center in İzmir province of Turkey between January 2017 and May 2018 with the diagnosis of AGI bleeding were retrospectively evaluated. Primary GI bleeding was not required as the cause of hospitalization and patients with GIS bleeding who were admitted for other causes were also included in the study. This is a retrospective study and both data during hospital stay and in the three months following discharge of patients presenting to the hospital between these dates were evaluated. Patients under 18 years and with incomplete access to medical data were not included in the study. In addition, consent was obtained for this study from the ethics committee for non-invasive clinical trials of XXXX Medical Faculty (date of consent: 13.07.2017 number: 2017/18-16). Patient data were kept confidential and the study was conducted in accordance with Helsinki declaration.

Patient related data were obtained from the hospital electronic medical records system (Probel; version 1.0; İzmir, Turkey) by entering GI bleeding related ICD diagnostic codes (ICD R58, ICD K92.0, ICD K92.1, ICD K92.2). Patient age, gender, bleeding symptoms at presentation, medications used and particularly anticoagulant drugs, related diseases, presence of prior GI bleeding, examination findings at presentation, hemogram and biochemical values, service admitted to because of bleeding, time interval between presentation and endoscopy, endoscopic findings and type of endoscopic treatment if applied, additional radiologic investigations if present, medical therapies applied for GI bleeding, blood transfusions, most recent diagnosis of GI bleeding, mortality or discharge, duration of hospital stay, final hemoglobin (Hb) and hematocrit (Htc) values at discharge, anemia treatment recommended at discharge and control $\mathrm{Hb}$ and $\mathrm{Htc}$ values within 3 months after discharge were evaluated.

According to WHO criteria, anemia during hospital admission and at discharge has been accepted as a hemoglobin $(\mathrm{Hb})$ level under $13 \mathrm{~g} / \mathrm{dL}$ in men and under $12 \mathrm{~g} / \mathrm{dL}$ in women ${ }^{12}$.

The primary endpoint of this study is to establish rates of anemia induced by blood loss from GI bleeding in patients presenting or followed with the diagnosis of GIS bleeding. The secondary endpoint is to establish whether patients found to have anemia received treatment for anemia at the hospital or at discharge.

Descriptive statistics were used for interpreting the data in our study. Data were analyzed using Statistical package for the Social Sciences (SPSS) (version 22.0; SPSS Inc., Chicago, IL, USA) package program. Numerical variables were summarized with percentage distribution and quantitative variables with mean and standard deviation. Mc Nemar test was used for dependent group analysis of the numerical variables. Compatibility was analyzed with Kappa. Repeated Measures Variance Analysis was used for dependent group analysis of quantitative variables. Significance level was $\mathrm{p}<0.05$.

\section{RESULTS}

Data of 197 patients admitted to our Hospital between January 2017 and May 2018 with the diagnosis of AGI bleeding were retrospectively analyzed.

When demographic data of 197 patients followed because of AGI bleeding were analyzed, 118 were male and 79 were female. Mean age of the 197 included patients was 68 . When bleeding sites of the patients followed with AGI bleeding were classified, 132 patients had upper GI bleeding, 57 had middle-lower GI bleeding and bleeding site could not be established in 8 patients because endoscopy could not be carried out due to of vital instability. 
It was detected that chronic liver disease was present in $12.1 \%$ (n:24) of the patients. It was observed that acute renal insufficiency developed in $46(23.4 \%)$ of the patients after GI bleeding. It was detected that 53 patients $(26.9 \%)$ had prior GI bleeding history.

The mean $\mathrm{Hb}$ level of 197 patients at the time of presentation is $9.3 \mathrm{~g} / \mathrm{dL}$. When the patients who were exitus (n:28), transferred to external medical center intensive care unit (n:3) and who refused the treatment were subtracted from 197 patients, the mean $\mathrm{Hb}$ level of the remaining 161 patients at the moment of discharge was found $10.1 \mathrm{~g} / \mathrm{dL}$. Anemia according to WHO criteria during discharge was detected in 147 patients $(91,3 \%)$. It was seen that anemia treatment was given to only $15(10,2 \%)$ of the 147 patients in whom anemia was detected. Within the 3 months following discharge, only $65(40,4 \%)$ of the 161 patients who had presented with A-GIS bleeding and were followed-up came for the control follow-up visit, the mean $\mathrm{Hb}$ level of these patients were found $10.7 \mathrm{~g} / \mathrm{dL}$ and it was seen that anemia continued in $80 \%$ of the patients at present.

Demographic data, AGI bleeding sites, Hb levels and anemia status of 197 patients with AGI bleeding are summarized in Table 1.

Hundred and thirty-one patients underwent upper GI endoscopy, 3 enteroscopy, 45 lower GI endoscopy, 8 upper and lower GI endoscopy, 2 upper, middle and lower GI endoscopy, and 8 patients could not undergo any procedures because of vital instability. The three most frequent causes of upper AGI bleeding were duodenal ulcer, gastric ulcer and esophageal variceal bleeding, respectively, and causes of upper AGI bleeding are summarized in Table 2 in order of frequency. The three most frequent causes of lower-middle AGI bleeding were hemorrhoids, diverticulae and angiodysplasias, respectively, and causes of lower-middle AGI bleeding are summarized in Table 3 in order of frequency.

Sixty nine patients underwent an endoscopic therapeutic intervention (47.8\% sclerotherapy, $15.9 \%$ argon plasma coagulation, $5.8 \%$ clip application, $5.8 \%$ band ligation, $24.6 \%$ mixed procedure). Mean hospital stay was $10 \pm 14$ days, and $67 \%$ of patients underwent transfusion with $3.5 \pm 5.89$ units of erythrocyte suspension during hospital stay. Of 197 patients followed with AGI bleeding, 28 died and 3 of 169 patients were referred to the intensive care unit of another hospital, 5 refused therapy, and 161 were discharged after their posthospitalization therapies were completed. Mean $\mathrm{Hb}$ levels of patients after follow up of AGI bleeding was $10,1 \mathrm{~g} / \mathrm{dL}$.

147 patients (91.3\%) (F 91.1\%, M 91.4\%, upper GI bleeding 92.8\%, middle GI bleeding 100\%, lower GI bleeding $87.2 \%$ ) had anemia during discharge. When frequency of anemia was viewed in terms of gender, the frequency of anemia having been found as 85/93 (91.3\%) in male patients and 62/68 (91.1\%) in female patients, meaningful relationship was not found between prevalence of anemia and gender $(\mathrm{p}>0.05)$. Having been found as 103/111 (92.8\%) in the patient group with upper AGI bleeding and as 44/50 (88\%) in the patient group with lower-middle AGI bleeding, meaningful relationship was not found in respect of frequency of anemia prevalence according to bleeding site $(\mathrm{p}>0.05)$.

It has been seen that there is a meaningful relationship between high BUN at presentation and elongated hospitalization with frequency of anemia prevalence $(\mathrm{p}<0.05)$.

It has been seen that there is a meaningful relationship between incidence of anemia and comorbid disease in the patients followed with GI bleeding $(\mathrm{p}<0.05)$ (Table-4). As this situation may be secondary to pre-existing chronic disease anemia, it suggests multiple drug use causing complicated lesions that will create bleeding susceptibility in GIS and chronic disease anemia and iron deficiency anemia could be overlapping. Reviewing the anemia parameters in the patients will be helpful for us to reveal this situation more clearly.

Fifteen patients noted to have anemia $(10.2 \%)$ were prescribed oral $(\mathrm{n}=12,7.8 \%)$ and parenteral $(\mathrm{n}=3,1.9 \%)$ iron therapy during discharge. A mean increase of $2,96 \mathrm{gr} / \mathrm{dL}$ was observed in Hb levels of the patients given oral treatment in a three-month period. Only 1 patient of the 3 patients given IV treatment came to control visit and it was seen that there was $1 \mathrm{gr} / \mathrm{dL}$ increase in $\mathrm{Hb}$ level.

65 of 161 patients (40.3\%) were re-evaluated in the first three months following discharge and anemia persisted 
in $80 \%$ of these. Of 15 patients receiving treatment for anemia, 11 came to control visits in the first 3 months after discharge and anemia was noted to resolve in $4(36.3 \%)$ patients. Again, 54 of 132 patients not receiving treatment for anemia following discharge came to control visits in the first 3 months after discharge and anemia was noted to resolve in $9(16.6 \%)$ patients. None of the patients followed after discharge required blood transfusion.

\section{DISCUSSION}

In our retrospective study, anemia was noted in approximately $92 \%$ of patients presenting with AGI bleeding at discharge and treatment for anemia was planned at discharge in only $10.2 \%$ of discharged patients and the large remaining patient group did not receive any treatment for anemia. It was also previously shown in the study of Bager et al. ${ }^{10}$ that $84 \%$ of patients presenting to the hospital with non-variceal upper AGI bleeding and discharged from intensive care unit in Denmark also had anemia during discharge and only $16 \%$ of patients received iron therapy. Because there are no guidelines about iron therapy that the patients followed with the diagnosis of AGI bleeding and with anemia will receive following discharge, the rate of patients receving iron therapy is rather low though the approach of clinicians is variable. Therefore, guidelines are needed on this subject and long term studies should be carried out about the course of anemia with long term iron therapy in these patients.

Similarly, anemia was noted in $91,3 \%$ of our patients and only 15 patients received iron therapy and further investigations were not carried out regarding anemia. This shows that clinicians do not need further investigations associating GI bleeding with IDA. But this will lead to failure to treat other causes of anemia in case of overlap of IDA with conditions like chronic disease anemia or $\mathrm{B}_{12} /$ folic acid deficiency. Another point is that if the patient does not have severe anemia, the clinician may not take anemia seriously and plan further investigation regarding anemia. It is important to investigate iron deficiency in patients with AGI bleeding, because it has been shown in the literature that in these patients a mean increase of $2 \mathrm{~g} / \mathrm{dL}$ in Hb levels has been observed with iron therapy in a 4 -week period following discharge ${ }^{11}$. In our study also, a mean increase of $2.96 \mathrm{~g} / \mathrm{dL}$ has been observed in Hb levels of the patients given oral treatment in a three-month period. Only 1 patient of the 3 patients given IV treatment came to control visits and it was seen that there was $1 \mathrm{gr} / \mathrm{dL}$ increase in $\mathrm{Hb}$ level.

In our study, a significant difference was not found between the rates of anemia in patients receiving $(63.6 \%)$ and not receiving (83.3\%) iron therapy after a 3-month follow up ( $>>0.05)$. However, mean hemoglobin level of patients receiving iron therapy when anemia was noted at discharge was found to be higher than that of patients not receiving therapy and this difference was statistically significant $(\mathrm{p}<0.05)$. In conclusion, iron therapy was shown to increase $\mathrm{Hb}$ levels and there may be many reasons for the lack of a significant difference between anemia rates of groups receiving and not receiving iron therapy. A follow up period shorter than 6 months being insufficient for filling iron depots is an important factor. Continuation of chronic low blood loss due to the persistence of the gastrointestinal lesion in the patient was also considered.

In addition, another factor for the failure of anemia to improve may be the low compliance of patients particularly to oral iron therapy. Selection of the type of iron therapy should depend on the clinical condition of the patient (primary GIS disorder, pathophysiology, inflammation, presence of co-morbidities and malabsorption). Timely and regular iron therapy will also reduce the need for blood tranfusions of the patients. In the case of persistence of anemia, it should also be considered that the lesion causing GIS bleeding has not fully healed during follow up and still causes blood loss.

Only approximately $1 / 3$ of our patients followed and discharged with the diagnosis of AGI bleeding came to control visits. Being uninformed about the condition of the patients who are lost to follow up is a major healthcare problem. In addition, anemia status of the patients before AGI bleeding is not fully known because this is a retrospective study. It cannot be predicted how this can affect mean Hb levels of the patients at discharge. Nevertheless, long term anemia status of the patients could not be evaluated because we evaluated 3 -month follow up data of the patients after discharge.

In conclusion, anemia is seen at a very high rate like $92 \%$ at discharge in the patients presenting with AGI 
bleeding in our retrospective study and most patients are discharged without receiving a prescription for the treatment of anemia. Control presentation during follow up is inadequate and anemia persists in $80 \%$ of patients coming to follow up visits. Studies with larger number of patients about the treatment and follow up to be conducted and guidelines providing consensus on this subject are needed.

\section{REFERENCES}

1. Hwang JH, Fisher DA, Ben-Menachem T, Chandrasekhara V, Chathadi K, Decker GA, Early DS, Evans JA, Fanelli RD, Foley K, Fukami N, Jain R, Jue TL, Khan KM, Lightdale J, Malpas PM, Maple JT, Pasha S, Saltzman J, Sharaf R, Shergill AK, Dominitz JA, Cash BD; The role of endoscopy in the management of acute non-variceal upper GI bleeding; American Society for Gastrointestinal Endoscopy (ASGE) Guideline. Gastrointest Endosc. 2012 Jun;75(6):1132-8.

2. Gurudu SR, Bruining DH, Acosta RD, Eloubeidi MA, Faulx AL, Khashab MA, Kothari S, Lightdale JR, Muthusamy VR, Yang J, DeWitt JM. The role of endoscopy in the management of suspected small-bowel bleeding; American Society for Gastrointestinal Endoscopy (ASGE) Guideline. Gastrointest Endosc. 2017 Jan;85(1):22-31.

3. Pasha SF, Shergill A, Acosta RD, Chandrasekhara V, Chathadi KV, Early D, Evans JA, Fisher D, Fonkalsrud L, Hwang JH, Khashab MA, Lightdale JR, Muthusamy VR, Saltzman JR, Cash BD. The role of endoscopy in the patient with lower GI bleeing; American Society for Gastrointestinal Endoscopy (ASGE) Guideline. Gastrointest Endosc. 2014 Jun;79(6):875-85.

4. Gralnek IM, Dumonceau JM, Kuipers EJ, Lanas A, Sanders DS, Kurien M, Rotondano G, Hucl T, Dinis-Ribeiro M, Marmo R, Racz I, Arezzo A, Hoffmann RT, Lesur G, de Franchis R, Aabakken L, Veitch A, Radaelli F, Salgueiro P, Cardoso R, Maia L, Zullo A, Cipolletta L, Hassan C. Diagnosis and management of nonvariceal upper gastrointestinal hemorrhage: European Society of Gastrointestinal Endoscopy (ESGE) Guideline. Endoscopy. 2015 Oct;47(10):1-46.

5. Akpınar H, Çetiner M, Keshav S, Örmeci N, Törüner M. Diagnosis and treatment of iron deficiency anemia in patients with inflammatory bowel disease and gastrointestinal bleeding: iron deficiency anemia working group consensus report. Turk J Gastroenterol 2017 Mar;28(2):81-87.

6. Gordon S, Bensen S, Smith R. Long-term follow-up of older patients with iron deficiency anemia after a negative GI evaluation. Am J Gastroenterol. 1996; 91:885-9.

7. Rockey DC, Cello JP. Evaluation of the gastrointestinal tract in patients with iron-deficiency anemia. N Engl J Med 1993; 329:1691-5.

8. Sahay R, Scott BB. Iron deficiency anaemia- how far to investigate? Gut 1993; 34:1427-8.

9. Schilling D, Grieger G, Weidmann E et al. Long-term follow-up of patients with iron deficiency anemia after a close endoscopic examination of the upper and lower gastrointestinal tract. Z Gastroenterol 2000; 38:827-31.

10. Bager P, Dahlerup JF. Lack of follow-up of anaemia after discharge from an upper gastrointestinal bleeding centre. Dan Med J. 2013 Mar;60(3): A4583.

11. Bager P, Dahlerup JF. Randomised clinical trial: oral vs. intravenous iron after upper gastrointestinal haemorrhage-a placebo-controlled study. Aliment Pharmacol Ther. 2014; 39:176-187.

12. WHO/UNICEF/UNU. Iron deficiency anemia: assessment, prevention and control. Report of a joint WHO/UNICEF/UNU consultation. Geneva: World Health Organization, 1998.

\section{Hosted file}

TABLE 1.docx available at https://authorea.com/users/336283/articles/461999-prevalence-ofanemia-and-clinical-approach-in-patients-discharged-after-gastrointestinal-bleeding

\section{Hosted file}

TABLE 2.docx available at https://authorea.com/users/336283/articles/461999-prevalence-ofanemia-and-clinical-approach-in-patients-discharged-after-gastrointestinal-bleeding

\section{Hosted file}


TABLE 3.docx available at https://authorea.com/users/336283/articles/461999-prevalence-ofanemia-and-clinical-approach-in-patients-discharged-after-gastrointestinal-bleeding

\section{Hosted file}

TABLE 4 new.docx available at https://authorea.com/users/336283/articles/461999-prevalenceof-anemia-and-clinical-approach-in-patients-discharged-after-gastrointestinal-bleeding 